\title{
A EUROPEAN BENCHMARKING OF VOLTAGE QUALITY REGULATION
}

\author{
Math BOLLEN \\ LTU - Sweden \\ math.bollen@1tu.se \\ Jasmina TRHULJ \\ AERS - Serbia \\ jasmina.trhulj@aers.rs
}

\author{
Yvonne BEYER \\ NMa - The Netherlands \\ Yvonne.Beyer@nma.nl \\ Riccardo VAILATI \\ AEEG - Italy \\ riccardo.vailati@gmail.com
}

\author{
Emmanouil STYVAKTAKIS \\ RAE - Greece \\ styvactakis@rae.gr \\ Werner FRIEDL \\ E-control - Austria \\ Werner.Friedl@e-control.at
}

\begin{abstract}
The Council of European Energy Regulators has been publishing Benchmarking Reports on the Quality of Electricity Supply since 2001. For the 2011 edition of the Benchmarking Report the 29 member countries of CEER were joined by the 9 NRAs from the Energy Community and the NRA from Switzerland. This paper contains the main results, findings and recommendations on voltage quality from the 2011 edition.
\end{abstract}

\section{INTRODUCTION}

The Council of European Energy Regulators (CEER) [1] periodically surveys and analyses the quality of electricity supply in its member countries (27 member states of the European Union, Iceland and Norway), addressing three major aspects: the availability of electricity (continuity of supply), its technical properties (voltage quality) and the speed and accuracy with which customer requests are handled (commercial quality).

These surveys and analyses take the form of CEER Benchmarking Reports on Quality of Electricity Supply. The first report was issued in 2001 [2], followed by the second, third and fourth editions in 2003, 2005 and 2008 respectively [3] [4] [5]. Similarly, information on the national regulations and its effects in the Energy Community were gathered by the Energy Community Regulatory Board (ECRB) in the 2009 ECRB Report on the Quality of Electricity Service Standards and Incentives in Quality Regulation [6].

In addition to National Regulatory Authorities (NRAs) from CEER member countries, the 9 NRAs from the Energy Community [7] and the National Regulatory Authority of Switzerland joined for the 2011 Benchmarking Report (BR) [8].

A detailed survey was sent out in March 2011 to the CEER member countries and the Energy Community Contracting Parties (CPs) to obtain information on all three aspects of quality of supply. The survey contained detailed questions about existing and planned regulations on quality of supply, monitoring practices as well as questions on existing quality levels.

In this paper, we present the main results from the 2011 edition as well as the recommendations from CEER and ECRB on voltage quality. The results on continuity of supply and commercial quality are presented in [9] and [10].

\section{LEGISLATION, REGULATION, STANDARDS}

\section{EN 50160 as a basis for regulation}

The European voltage-characteristics standard, EN 50160, remains the basic instrument for voltage quality regulation in Europe. This document sets limits for a number of voltage disturbances: power frequency; supply voltage variations; flicker; unbalance; harmonic voltage; and mains signalling voltages.

To improve the standard and to increase its usefulness as a harmonized regulatory framework, a cooperation between CEER and CENELEC was started in 2006. This led to the publication of a new version of the standard EN 50160:2010 with the following improvements compared to the earlier edition:

$\checkmark \quad$ an improved structure dividing continuous phenomena and voltage events;

$\checkmark$ improved definitions for voltage dips and swells;

$\checkmark \quad$ standardized classification tables for voltage dips and swells;

$\checkmark \quad$ the applicability of the standard up to and including 150 $\mathrm{kV}$;

$\checkmark$ the removal of a note allowing supply voltage variations outside any limits when customers are connected "in remote areas with long lines or not connected to a large interconnected network";

$\checkmark$ improved limits for supply voltage variations in the medium voltage network;

$\checkmark$ the removal of ambiguous indicative levels for voltage events (e.g. "thousands of voltage dips") from the normative part of the standard.

The survey in the Energy Community has shown that CPs are undertaking important activities towards implementation of EN 50160 as the main instrument for voltage quality regulation. EN 50160 is implemented by most CPs, mainly as a voluntary standard but also through national legislation and regulation, either through a reference to EN 50160 or by adopting the limits given in EN 50160. However, voltage quality regulation is still primarily applied on LV and MV 
level and predominantly for supply voltage variations.

\section{Regulation beyond EN 50160}

The CEER survey reveals that EN 50160 is used for regulation in many countries. However, a growing number of countries are introducing national requirements on voltage quality that deviate from EN 50160.

In the Energy Community, all the CPs have reported national voltage quality requirements that differ from EN 50160. Different requirements are implemented for different reasons, for example historical, different network characteristics or introducing new stricter limits.

National requirements in the Energy Community CPs as well as in the CEER member countries are generally stricter than those set by EN 50160 .

As an example, Table I shows that for supply voltage variations, most countries use a 10 -minute integration period to calculate the r.m.s. voltage. The exceptions are Hungary and Norway, where a 1-minute period is used. Some countries (such as Hungary and Spain) use 95\% limits, as in EN 50160, but a smaller permissible range of voltage variations. Other countries allow a $10 \%$ deviation from the nominal voltage, as in EN 50160, but during 99.9 or $100 \%$ of the time, for example, The Netherlands (99.9\% for HV) and Sweden $(100 \%)$. Some countries apply two-stage limits, either a larger range for 1-minute than for 10-minute r.m.s. values (Hungary) or a larger range for $100 \%$ than for $95 \%$ of the time (The Netherlands).

Besides the limits shown in Table I, different time and limits are applied in Italy for HV networks in normal, alarm, emergency and restoration conditions as well as temporary islanding operation of normally interconnected MV networks.

TABLE I

VOLTAGE QUALITY REGULATION DIFFERENT FROM EN 50160 - SUPPLY VOLTAGE VARIATIONS

\begin{tabular}{|c|c|c|c|}
\multicolumn{1}{|c}{ EN $50160-$ SUPPLY VOLTAGE VARIATIONS } \\
\hline Period & Time & Limit & Country (voltage level) \\
\hline $10 \mathrm{~min}$ & $95 \%$ & $\pm 7.50 \%$ of $\mathrm{U}_{\mathrm{n}}$ & $\mathrm{HU}(\mathrm{LV})$ \\
\hline $10 \mathrm{~min}$ & $100 \%$ & $\pm 10 \%$ of $\mathrm{U}_{\mathrm{n}}$ & $\mathrm{HU}(\mathrm{LV}), \mathrm{SE}(\mathrm{HV}, \mathrm{MV}, \mathrm{LV})$ \\
\hline $1 \mathrm{~min}$ & $100 \%$ & $+15 \% /-20 \%$ of $\mathrm{U}_{\mathrm{n}}$ & $\mathrm{HU}(\mathrm{LV})$ \\
\hline $10 \mathrm{~min}$ & $95 \%$ & $\pm 5 \%$ of $\mathrm{U}_{\mathrm{n}}$ & $\mathrm{PT}(\mathrm{HV})$ \\
\hline $10 \mathrm{~min}$ & $95 \%$ & $\pm 7 \%$ of $\mathrm{U}_{\mathrm{n}}$ & $\mathrm{ES}(\mathrm{MV}, \mathrm{LV})$ \\
\hline $1 \mathrm{~min}$ & $100 \%$ & $\pm 10 \%$ of $\mathrm{U}_{n}$ & $\mathrm{NO}(\mathrm{LV})$ \\
\hline $10 \mathrm{~min}$ & $95 \%$ & $\pm 10 \%$ of $\mathrm{U}_{\mathrm{n}}$ & $\mathrm{NL}(\mathrm{MV})$ \\
\hline $10 \mathrm{~min}$ & $100 \%$ & $+10 \% /-15 \%$ of $\mathrm{U}_{n}$ & $\mathrm{NL}(\mathrm{MV})$ \\
\hline $10 \mathrm{~min}$ & $99.9 \%$ & $\pm 10 \%$ of $\mathrm{U}_{\mathrm{n}}$ & $\mathrm{NL}(\mathrm{HV})$ \\
\hline $10 \mathrm{~min}$ & $95 \%$ & $+6 \% /-10 \%$ of $230 \mathrm{~V}$ & $\mathrm{IT}(\mathrm{LV})$ \\
\hline
\end{tabular}

\section{Further improvements needed in EN 50160}

CEER retains the view that the standard EN 50160 can be satisfactory from a regulatory point of view, only if certain further improvements are made. CEER considers the following improvements necessary:

$\checkmark \quad$ an effective extension to the high voltage networks (with effective limits and requirements) and the consideration of extra high voltage networks;

$\checkmark \quad$ the adoption of new limits for supply voltage variations in distribution networks (especially in low voltage networks);

$\checkmark$ the introduction of limits for voltage events, taking into account the different characteristics of the European networks; for voltage dips and voltage swells one or more responsibility-sharing curves should be defined;

$\checkmark \quad$ a general framework for sharing the voltage quality responsibilities between network companies, equipment manufacturers and users.

The regulation of voltage quality will require further development, especially against the background of the expected large implementation of distributed generation.

CEER believes that harmonized voltage quality requirements are necessary. Unless the above-mentioned improvements are implemented as soon as possible, the standard EN 50160 will miss its objective to harmonize the voltage quality standards and performances across the European electricity networks, due to the fact that national deviations in regulation will increase further. Further strengthening of the voltage quality regulation in individual member countries, followed by attempts to harmonize the differing regulations, is the only alternative.

Those Energy Community CPs that have not adopted EN 50160 are encouraged to do so. Implementing provisions in legislation that are consistent or stricter than EN 50160 is recommended. Those CPs that already adopted but have not translated EN 50160 should make the effort to translate EN 50160 with a view to have precise definitions in national language and to allow further development of terminology. CPs that have adopted or will adopt EN 50160 should adopt the standard fully, including all voltage characteristics and all voltage levels.

Considering that the EN 50160 introduction process in the Energy Community is yet in an early stage, joint activities on the implementation and harmonization in line with the CEER practice are recommended in the Energy Community.

\section{Voltage quality verification issues}

The network users in the majority of the European countries, including Energy Community CPs, are entitled to a verification of the actual voltage quality levels at their point of connection. Even where this is not compulsory, the network operators in several countries offer such verification. Still, this good practice is not adopted in all countries. Only one country (Slovenia) reported a predefined charge for voltage quality verification measurements. In some countries, the customer pays only if the measurements are found to be within the 
limits.

Further, the CEER survey reveals that increasing attention is given to providing individual users with information on voltage quality at their point of connection (or close to it). This includes information for users to be connected. The obligation for network operators to provide individual information on and verification of voltage quality upon a user's request should be adopted by all countries. This obligation should be accompanied by a detailed description of the procedure by the network operator so that all relevant information is available to the customer, including the cost of the service (if any).

Special emphasis should be given in the Energy Community to the introduction of legal obligations for network operators to provide individual voltage-quality verification and information to users.

With respect to individual voltage quality issues, customer compensation, penalties or other sanctions are applied in the majority of the reporting CEER member countries. Three categories are identified here:

$\checkmark$ Customer compensation by the network operator according to the conditions of a contract between the customer and the network operator,

$\checkmark$ Customer compensation by the network operator in case of a violation of the overall voltage quality limits or in case of a late response to a measurement request by a customer, and

$\checkmark \quad$ Monetary penalties applied to the network operator in case of voltage quality problem mishandling (e.g. late response, problem not resolved, mitigation measures ordered by the NRA are not taken).

In the majority of the Energy Community CPs, monetary penalties, customer compensation or other types of sanctions are not envisaged in the legislation or regulation and consequently not applied in case of violation of voltage quality limits.

CEER recommends that the NRA or the network operator keeps statistics on complaints and verification results and correlates these with the results from continuous voltage quality monitoring (if in place). NRAs should use such statistics for regulatory decisions regarding voltage quality, while network operators should use it for identifying areas that need improvements or further investigation.

\section{VOLTAGE QUALITY DATA}

Actual levels of voltage dips are reported in the 2011 BR for 6 countries: France, Hungary, Italy, The Netherlands, Portugal and Slovenia. To enable a direct comparison between the data from different countries, an "indicative responsibility-sharing curve" has been introduced to distinguish between major dips (dips below the curve) and minor dips (dips above the curve). The indicative responsibility curve shown in Fig. 1 is close to equipment immunity Class $\mathrm{C}$ as proposed by CIGRE/CIRED/UIE joint working group C4.110 [11], a recent proposal by the Italian regulator for the classification of voltage dips, and one of the curves used in the Swedish regulation on voltage dips [12]. The difference is that, according to the curve in Fig. 1, the $80 \%$ border is extended all the way up to 1 minute. Table II shows the average number of major dips per location per year for those countries that provided data on voltage dips.

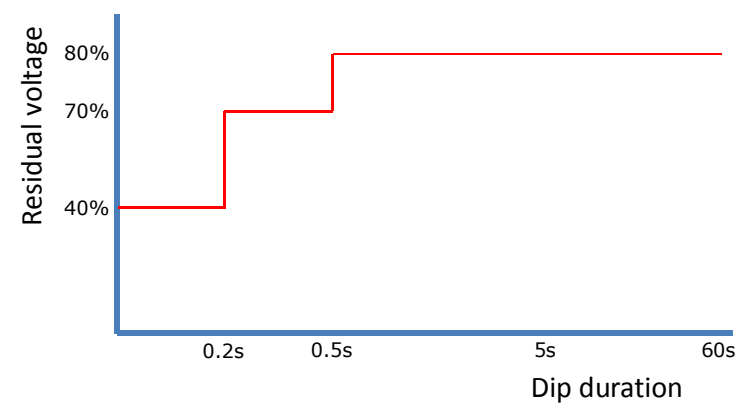

Fig. 1. Indicative responsibility-sharing curve for voltage dips, defining major and minor dips

TABLE II

NUMBER OF MAJOR DIPS IN DIFFERENT COUNTRIES (PER MONITOR-YEAR)

\begin{tabular}{|l|c|c|c|}
\hline Country & 2008 & 2009 & 2010 \\
\hline France (transmission) & 2.1 & 2.5 & 1.7 \\
\hline Hungary (LV) & & 25.2 & \\
\hline Hungary (MV) & & 13.3 & \\
\hline Italy (MV) & 26.6 & 18.8 & 15.9 \\
\hline Italy (HV) & & & 3.3 \\
\hline The Netherlands (HV) & 1.0 & 2.0 & 2.3 \\
\hline Portugal (HV) & 18.7 & 15.3 & \\
\hline
\end{tabular}

The number of major dips presented in Table II has been obtained by summing the dips below the responsibility sharing curve and applying a normalization factor consisting of the number of locations at which voltage dip measurements were performed and the monitoring duration at each measurement location. Table II therefore shows the average number of major dips per measurement location per year. The comparability of the numbers is thus only limited by the voltage level in which the measurements were performed and by the differences in network structure. Both of these factors have an impact on the expected number of voltage dips. It should also be noted that the table shows the average number of dips over all measurement locations. The spread between individual locations is much larger [11]. This is also confirmed by other studies including the monitoring results from France and Italy presented in the BR.

The table shows large differences in the number of major dips 
in the networks in the different reporting countries. However, the number of countries and the number of years are too small to draw any further conclusions.

\section{CONCLUSIONS}

A number of findings and recommendations were obtained from the survey results, the analysis of the survey results, and the subsequent discussions within CEER and the Energy Community. Strongly summarized formulations of those findings and recommendations are listed below. For specific details and exact formulations, the reader is referred to the text of the 2011 BR [8].

$\checkmark \quad$ Finding \#1: Voltage characteristics are regulated through EN 50160 in combination with stricter national requirements in most of the countries.

$\checkmark$ Recommendation \#1: Implement voltage quality requirements for all voltage levels and all phenomena, particularly for voltage events. Further improve EN 50160 as a harmonized instrument for voltage quality regulation. Use the results from cost-estimation studies of voltage disturbances when deciding where to focus regulation.

$\checkmark \quad$ Finding \#2: Verification of and information on the actual voltage quality levels at individual connection points is guaranteed in most of the responding countries.

$\checkmark$ Recommendation \#2: Ensure individual voltage quality verification and information.

$\checkmark$ Finding \#3: Regulation of emission levels of network users varies across countries.

$\checkmark$ Recommendation \#3: Set reasonable emission limits for network users.

$\checkmark \quad$ Finding \#4: Many countries have continuous voltage quality monitoring systems.

$\checkmark$ Recommendation \#4: Introduce a voltage quality monitoring obligation into national legislation and regulation. Broaden the scope of continuous voltage quality monitoring programs. Exploit the possibilities offered by smart meters without excessive price increase for customers.

$\checkmark \quad$ Finding \#5: Differences exist between countries in the choices of monitored voltage quality parameters and in the reported voltage dip data.

$\checkmark$ Recommendation \#5: Define harmonized characteristics and indices for voltage dips.

$\checkmark$ Finding \#6: Voltage quality data is publicly available in some European countries.

$\checkmark$ Recommendation \#6: Ensure availability and regular publication of voltage quality data.

The BRs have demonstrated the importance of a continued exchange of information on quality indicators, actual quality levels, standards, regulatory mechanisms and strategies. Their publication has facilitated obtaining information on the regulation of voltage quality and on the effects of this regulation in different European countries. Good practices for monitoring and regulating voltage quality in electrical networks are described in the $2011 \mathrm{BR}$ and summarized in this paper. The findings and recommendations will form a basis for further development of voltage quality regulation and monitoring. It is important that NRAs continue exchanging best practices for regulating electrical network industries, as done in the BRs.

\section{ACKNOWLEDGEMENT}

The contributions are acknowledged from many others to the material that formed the basis for this paper, especially the other members of the Electricity Quality of Supply and Smart Grids Task Force within CEER and the ECRB Customer Working Group within the Energy Community.

The text of this paper is based on the text in the 5th Benchmarking Report on Quality of Electricity Supply. Where the text of this paper deviates from the text of the Benchmarking Report, it is the personal opinion of the authors and not necessarily the opinion of CEER or ECRB, neither of the national regulatory authorities involved.

\section{REFERENCES}

[1] Council of European Energy Regulators, http://www.energy-regulators.eu

[2] Quality of Electricity Supply: Initial Benchmarking on Actual Levels, Standards and Regulatory Strategies", CEER, April 2001.

[3] Second Benchmarking Report on Quality of Electricity Supply, CEER, September 2003.

[4] Third Benchmarking Report on Quality of Electricity Supply 2005, CEER, December 2005.

[5] 4th Benchmarking Report on Quality of Electricity Supply, CEER, December 2008.

[6] ECRB Report on the Quality of Electricity Service Standards and Incentives in Quality Regulation, ECRB, July 2009.

[7] Energy Community, http://www.energy-community.org

[8] 5th Benchmarking Report on Quality of Electricity Supply, CEER, December 2011.

[9] W. Friedl et al., A European benchmarking of continuity of supply regulation. This conference.

[10] A. Mozsolics, et al., A European benchmarking on commercial quality regulation. This conference.

[11] CIGRE Technical Brochure TB 412, Voltage dip immunity of equipment and installations, April 2010. www.uie.org; www.e-cigre.org

[12] L. Ström, M.H.J. Bollen, R. Kolessar, Voltage quality regulation in Sweden, CIRED 2011. 